\title{
Dating geologic gold deposits and authenticating a Greek gold tiara, an ancient gold chalice, and swimming dragon artifacts of the Chinese Han dynasty
}

\author{
Otto Eugster ${ }^{1}$
}

Received: 27 March 2018 / Accepted: 9 June 2018 / Published online: 21 June 2018

(C) The Author(s) 2018

\begin{abstract}
In this work, we present the application of the uranium, thorium-helium (U,Th-He) dating method to two different types of gold objects: geologic gold deposits and archeological gold objects. Direct dating of geologic gold deposits is difficult without assuming contemporaneity between gold and datable hydrothermal minerals. We show that our results indicate that the applied dating method opens a new perspective for the dating of gold deposits without assuming contemporaneity between gold and datable hydrothermal minerals. The second application of our dating method is authenticating archeological gold objects. This is a major problem, as gold is probably the most difficult material in terms of detecting modern forgeries. The feasibility of this application was mentioned in 1996 in an earlier article in Gold Bulletin, Eugster (Gold Bull 29:101-104, 1996). In the past two decades, we applied the U,Th-He dating method to numerous gold antiquities in order to determine the time of their formation or their latest melting process, respectively. Gold always contains traces of uranium and thorium that produce alpha particles by radioactive decay which transform to helium. When gold is molten to manufacture an art object, the helium is lost, but gets stored again when the gold cools down. Thus, the radioactive clock starts anew. Here, we present the results for direct dating of gold deposits and for the authentication of some of the most remarkable artifacts and describe their history.
\end{abstract}

Keywords Gold antiquities · Geologic gold deposits $\cdot$ Uranium,thorium-helium dating $\cdot$ Noble gas mass spectrometry

\section{Introduction}

The time when gold present in a gold mine or a gold nugget found in a gold deposit was formed can be determined using a dating method based on the radioactive decay of uranium and thorium into helium. When gold crystals are formed in a cooling hydrothermal fluid in the Earth's interior, also uranium and thorium atoms are included in the crystal lattice. These elements are radioactive and decay by emitting alpha particles. They capture two electrons and become helium atoms. This method of directly dating geologic gold deposits is a significant improvement over dating accessory minerals and assuming contemporaneity between gold and these minerals.

Otto Eugster

eugster@space.unibe.ch

1 Physics Institute, University of Bern, Bern, Switzerland
The same method can be applied to antique gold objects for which the time of manufacturing is unknown. This research and application to gold antiquities is important because gold is probably the most difficult material in terms of detecting modern forgeries, as no patina is formed on its surface. If an art object is manufactured by melting of gold, the helium produced by the decay of uranium and thorium since the gold existed is degassed. After the gold cooled down, helium is stored again within the crystal lattice. Because the decay constants of uranium and thorium are known, the time of the last melting process for the gold can be determined by measuring the uranium, thorium, and helium concentrations.

The first attempt to date gold objects using the U,Th-He dating method was performed in 1992 for alpine vein-type and placer gold $[1,2]$. The reason and the motivation for such an endeavor have been described by Jack Ogden [3]. In the following years, we presented the noble gas, $\mathrm{K}, \mathrm{U}$, and $\mathrm{Pb}$ contents in numerous native gold samples originating from alpine, South African, and South American deposits [4, 5]. The comparison of U/Th-He ages of gold crystals from the Santa Elena 
gold mine in Venezuela with those of faked gold crystals appearing on the mineral market purported to originate from this mine was published in 1996, showing that this dating method is a powerful tool to detect forgeries [6]. We tested the faked specimens and found only extremely little helium, as the time for helium production from uranium and thorium was too short in contrast to the real gold crystals from the mine that yielded a large amount of helium. Based on these studies we suggested that it might be possible to apply the U/Th-He dating method to antique gold objects. Inspired by our work, Kossolapov and coworkers [7] used a specifically designed mass spectrometer for extremely low helium quantities to test gold samples of archeological (Maikop and Scythian Collections of the Hermitage Museum, St. Petersburg, Russia) and modern gold.

\section{Materials and methods}

\section{Dating of geologic gold deposits}

Samples of about $50 \mathrm{mg}$ of gold material were loaded into a molybdenum crucible and heated up to the melting point of gold of $1064{ }^{\circ} \mathrm{C}$. At this temperature, the helium gas is released from the gold material. It was cleaned from all other gases using charcoal and titanium getters and introduced into the mass spectrometer usually used for meteorite and lunar sample analyses. The system blank was always less than 1 $\%$ of the sample gas. The $\mathrm{U}$ and $\mathrm{Th}$ analyses were performed at the Geologic Institute of the University of Bern by Jan Kramers using aliquot samples of the material used for the He analyses.

\section{He, U, and Th analyses for antique gold objects}

Usually we obtain a sample of about $30 \mathrm{mg}$ of an antique object for the determination of its authenticity. The sample is cleaned and etched in aqua regia in order to remove possible superficial pollution. The He content of antique gold objects that were manufactured a few thousand years ago is orders of magnitude lower than the He content of geologic samples with ages of many millions of years. Therefore, we acquired in 2005 a mass spectrometer, specially built by the company SPECTRON in St. Petersburg, for the measurement of extremely low He amounts (Fig. 1).

A sample of a few milligrams of a gold object is heated in the instrument to a temperature of $950{ }^{\circ} \mathrm{C}$ at which the helium escapes; the gold, however, does not melt. After the He analysis, we give the sample for the $\mathrm{U}, \mathrm{Th}$, and other element determinations to our colleague at the Geologic Institute of the University of Bern (Igor Villa) or to those at the Curd Engelhorn Zentrum for Archaeometry in Mannheim (Michael Brauns and Ernst Pernicka).

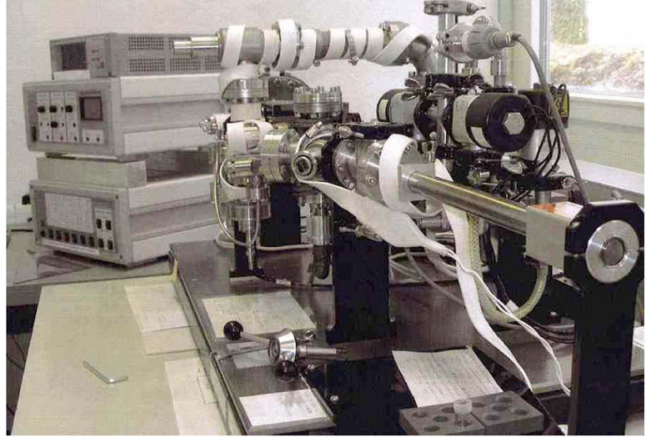

Fig. 1 Mass spectrometer for helium analyses

\section{Calculation of the time of manufacturing of an antique gold object}

How come that the time of manufacturing of an antique object can be determined based on the analysis of uranium, thorium, and helium? Based on the concentrations of these elements, the age of a gold object can be calculated using the formula

$T=\left[{ }^{4} \mathrm{He}\right] /\left(3.243 \times 10^{6} \times[\mathrm{U}]+7.705 \times 10^{5} \times[\mathrm{Th}]+4.018 \times 10^{3}[\mathrm{Sm}]\right)$

where ${ }^{4} \mathrm{He}$ is inserted in atoms per gram and $\mathrm{U}, \mathrm{Th}$, and $\mathrm{Sm}$ in parts per million. The Sm concentration is adopted to be $0.3 \mathrm{ppm}$ [Ernst Pernicka, personal communication]. The U/ Th-He age $T$ results in years. For the derivation of this formula and for the decay constants of the radionuclides and their relative abundances, we refer to our previous publication [8].

\section{Results}

\section{Geologic gold deposits}

The He, U, and Th data for samples originating from alpine, South African, and South American deposits were presented earlier [4-6] but without the corresponding U/Th-He ages shown in Table 1.

The obtained U/Th-He ages for the samples in Table 1 are consistent with the geologic period of the respective gold deposits. These results indicate that this dating method opens a new perspective for the dating of gold deposits without assuming contemporaneity between gold and datable hydrothermal minerals.

\section{Antique gold objects}

In order to apply the U/Th-He method on antique gold objects, we have to be able to detect $10^{-18} \mathrm{~g}$ (the billionth part of a billionth gram) helium. For antique gold objects, the decay time for uranium and thorium is only a few thousand years in contrast to millions of years for geologic gold. Furthermore, only few milligrams of gold material of the valuable objects are available. 
Table 1 Dated geologic gold deposits

\begin{tabular}{|c|c|c|c|c|c|c|c|}
\hline Sample & Locality & Geologic period & Geologic time & $\mathrm{He}($ atoms/g) & $\mathrm{U}(\mathrm{ppb})$ & Th (ppb) & $\begin{array}{l}\mathrm{U} / \mathrm{Th}-\mathrm{He} \\
\text { age (years) }\end{array}$ \\
\hline Krumpelgraben placer gold & Switzerland & Tertiary & $32 \mathrm{Ma}$ & $1.4 \times \mathrm{E} 14$ & 1300 & 100 & $33 \mathrm{Ma}$ \\
\hline Elvo river placer gold & Italy & Tertiary & $32 \mathrm{Ma}$ & $2.2 \times \mathrm{E} 13$ & 310 & 34 & $21 \mathrm{Ma}$ \\
\hline Brusson Gold Mine & Italy & Tertiary & $32 \mathrm{Ma}$ & $7.0 \times \mathrm{E} 13$ & 400 & 900 & $35 \mathrm{Ma}$ \\
\hline Lily Gold Mine & South Africa & Archean & $3800-2500 \mathrm{Ma}$ & $2.7 \times \mathrm{E} 14$ & 27 & 2.3 & $2980 \mathrm{Ma}$ \\
\hline Sabie Pilgrims Rest Gold Field & South Africa & Proterozoic & $2500-542 \mathrm{Ma}$ & $1.34 \times \mathrm{E} 14$ & 32 & 180 & $550 \mathrm{Ma}$ \\
\hline $\begin{array}{l}\text { East Driefontein Gold Mine } \\
\text { Ventersdorp Contact Reef }\end{array}$ & South Africa & Archean & $3800-2500 \mathrm{Ma}$ & $1.2 \times \mathrm{E} 17$ & $1.5 \times \mathrm{E} 4$ & $1.5 \times \mathrm{E} 43)$ & $1990 \mathrm{Ma}$ \\
\hline $\begin{array}{l}\text { Middle Elsburg Formation } \\
\text { UE1A Reef }\end{array}$ & South Arica & Late archean & $2500 \mathrm{Ma}$ & $1.82 \times \mathrm{E} 18$ & $3.2 \times \mathrm{E} 5$ & 1 x E5 3) & $1630 \mathrm{Ma}$ \\
\hline Diamantina Gold Mine & Brazil & Neo Proterozoic & $524 \pm 16 \mathrm{Ma}$ & $3.35 \times \mathrm{E} 13$ & 11.5 & 33.1 & $523 \mathrm{Ma}$ \\
\hline Santa Elena & Venezuela & Paleozoic-Mesozoic & $542-65.5 \mathrm{Ma}$ & & & & \\
\hline Gold Mine & & & & $1.67 \times \mathrm{E} 13$ & 12.1 & $403)$ & $234 \mathrm{Ma}$ \\
\hline Gold Mine (Fake) & & & & $5.4 \times \mathrm{E} 10$ & 8.5 & $303)$ & $1.0 \mathrm{Ma}$ \\
\hline
\end{tabular}

Typical experimental errors: $\mathrm{He}-10 \%, \mathrm{U}-10 \%$, Th-30\%, U/Th-He age-30\%

We applied the U,Th-He method to numerous antique gold objects and to some forgeries [8,9]. The consequences of the possibility to detect forgeries among antiquities was commented by Phil Ball [10] by referring to the story of the gold tiara acquired for a large sum of money on April 1 (!) 1896 by the director of the Louvre in Paris. The tiara had allegedly given more than two thousand years ago to the Scythian king Saitapharnes as part of a bribe not to attack the Greek colony of Olbia. Immediately, doubts about the authenticity of the tiara surfaced. Art historians questioned the style, the design, and the perfect condition of the tiara. In fact, a few years later, the Russian goldsmith Israel Rouchomovsky knocked at the door of the director and said: "I made the tiara." He was asked to reproduce a part of the tiara and could prove that his claim was correct. The goldsmith explained that he had been commissioned by an art dealer to make the tiara, who first tried to turn it over to the art museum of Vienna, where it was rejected as being too expensive, but obviously was more successful at the Louvre. In 1954, the Greek tiara was included in the "Salon of Fakes "along with eight Mona Lisas. If the dating method applied at the Physics Institute of the University of Bern had existed already at the beginning of the last century, it would have saved the Louvre its embarrassment.

We now present the investigations of the most remarkable antique gold objects that we did not publish before.

\section{The Greek tiara, a laurel wreath}

As chance happens, some months ago, we obtained another Greek (maybe Scythian) tiara from a gallery in Paris for testing its authenticity (Fig. 2).

This tiara is completely different from the tiara of the Russian goldsmith. It is a laurel wreath, as it was usually presented to an Olympic champion in the third century B.C. Also for this tiara there are doubts: one of the consulted art historians judged it as a forgery, another one as authentic. Therefore, our opinion was asked.

In the presence of the gallery owner, we took a small sample of this object. Dating by using the U,Th-He method revealed that the tiara was manufactured $2700 \pm 1000$ years ago. Reasons for the large experimental uncertainty are the extremely low concentrations of uranium and thorium and thus very low amounts of helium, close to the detection limit of the mass spectrometer used for the helium analyses.

\section{The gold chalice}

"Would you be willing to come to Liechtenstein in order to take a sample of an antique gold chalice for testing its authenticity?" the author of this article was asked several years ago by the representaive of a private Collection. We agreed and were fascinated by the beauty of the chalice (Fig. 3).

The stylistic elements testify to the highest artistic skill in the representation of Greek mythology. The height of the

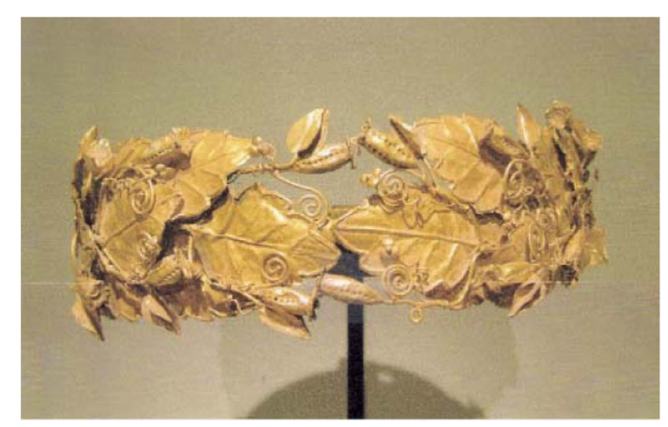

Fig. 2 Greek tiara, a laurel wreath 


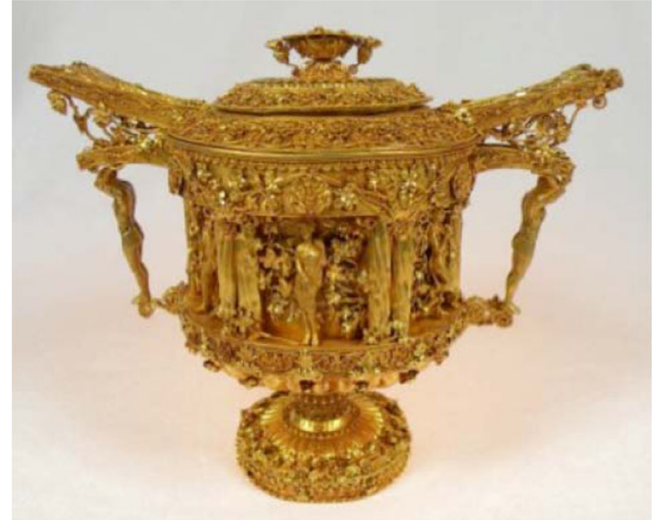

Fig. 3 Gold chalice

chalice is about $20 \mathrm{~cm}$ and its weight $730 \mathrm{~g}$. The chemical analysis by our colleagues in Mannheim yielded $86 \%$ gold, $11 \%$ silver, and $3 \%$ copper, typical for antique gold. The art historic examination comes to a time of manufacturing in the third or fourth century B.C.

The client wanted to have a confirmation of this time of manufacturing. Independent of the artistic and commercial value on the antiquity market, we agreed on a fixed price for the expertise. This price just covers the costs of the lab technicians, the external chemical analyses, the rent of the lab, and the instrument costs. With a higher price we would price us out of the market. The price cannot be dependent on the outcome of the testing, as we would become dubious.

We analyzed two samples and the conclusions were clear. The U/Th-He age is $3300 \pm 1100$ years, that is, it is consistent with the art historic information. Also, the contents of the trace elements are typical for antique gold objects. In particular, the cadmium content is very important, because modern forgers use the addition of cadmium to cause better fusibility of the gold and working the material becomes easier. A cadmium content of more than a tenth of a permil points to a modern forgery. Our analysis of the chalice yielded six times less.

Our client was happy and gave us two more objects for testing. One of them, a beautiful oil lamp, turned out to be ancient. The other one contained no helium, showing it was manufactured in modern times. A specialist for the evaluation of the price that the chalice could achieve at an auction came to an outstandingly high price. At that time, we obtained numerous specimens of Chinese gold artifacts from a gallery in Virginia, USA. The scientific director of this gallery, Melanie Roy, confirmed that such a high price for antique gold objects is possible: "You yourself have dated for us eight Chinese gold artifacts that belong to a collection of 11 objects. All together were estimated by experts to be 450 million dollars worth. They are the "swimming dragon artifacts" originating from the Chinese Han dynasty (206 B.C. -220 A.D.). In fact, we found in our documents the expertise of the years 2010 2012 for these eight gold objects and did not realize at this time that all of them show the ornament of a swimming dragon."

\section{The swimming dragon artifacts of the Chinese Han dynasty}

All objects are vessels consisting mainly of gold with turquoise inlay, granulation, and filigree in the shape of dragons in water (Fig. 4).

Art historians estimate their time of manufacturing around 50 A.D. In the mythology of China, the water dragons, as well
Fig. 4 The swimming dragon artifacts of the Chinese Han dynasty. (1) Gold lidded bowl. (2) Lidded bowl, inlaid with garnet. (3) Imperial gold jiu zun. (4) One of a pair of lidded gold $h u$-form vessels. (5) One of a pair of gold censors. (6) One of a pair of fang $h u$-form vessels. (7) One of a pair of jade censors
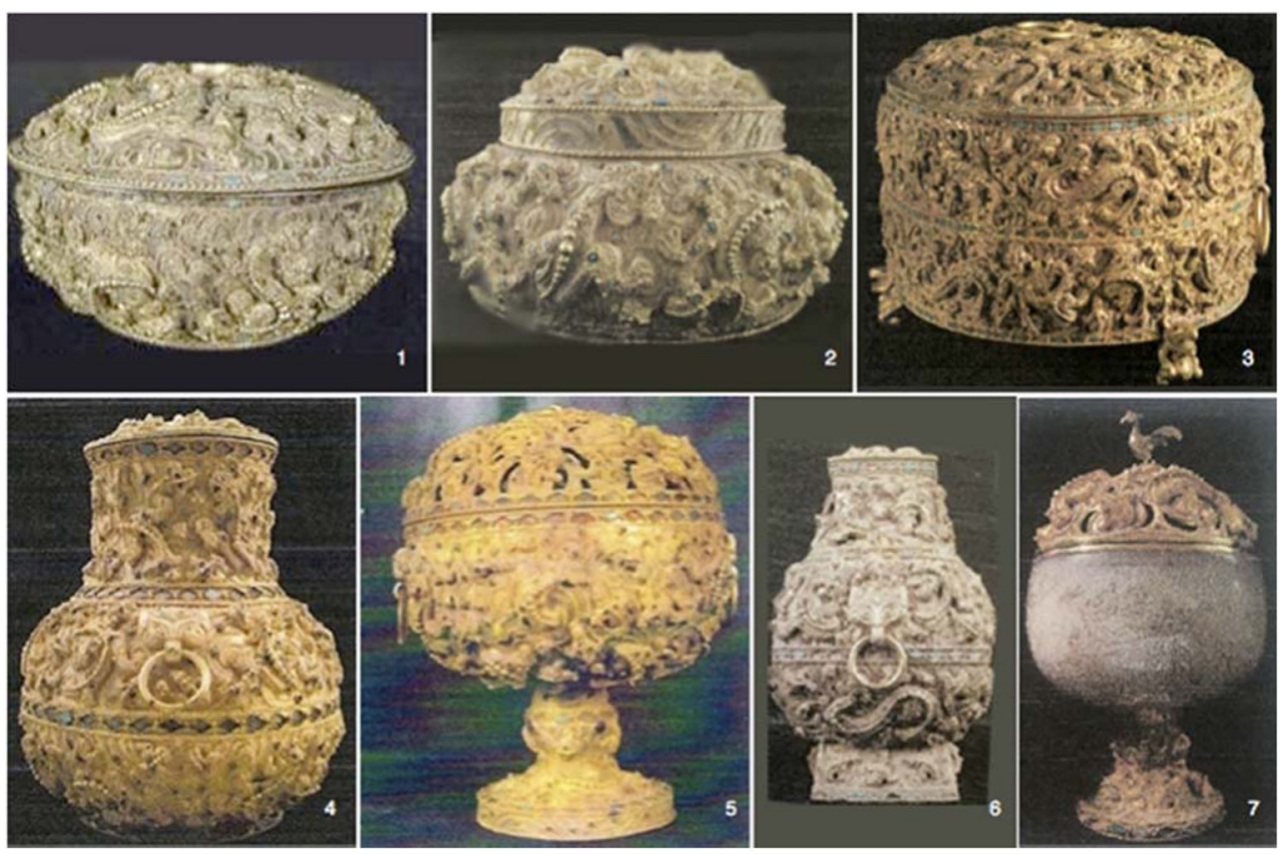
Table 2 Dated antique gold objects described in this work

\begin{tabular}{lclll}
\hline Object, object number & He (atoms/g) & $\mathrm{U}(\mathrm{ppb})$ & Th (ppb) & U,Th-He age (years) \\
\hline Golden laurel wreath & $4.6 \times 10^{6}$ & 0.12 & 0.11 & $2700 \pm 1000$ \\
Golden chalice & $3.6 \times 10^{7}$ & 2.9 & 0.24 & $3300 \pm 1100$ \\
Swimming dragon artifacts of the Chinese Han dynasty & & & \\
1. Lidded bowl, 3788 & $2.3 \times 10^{7}$ & 1.08 & 6.1 & $2400 \pm 800$ \\
2. Lidded bowl, 3835 & $8.0 \times 10^{7}$ & 4.80 & 7.1 & $3600 \pm 1800$ \\
3. Imperial gold jiu zun, 3893 & $2.4 \times 10^{7}$ & 0.86 & 4.1 & $3400 \pm 1500$ \\
4. Gold hu-form vessel, 3959 & $2.7 \times 10^{7}$ & 1.94 & 5.6 & $2300 \pm 700$ \\
5. Gold censor, 4006 & $3.0 \times 10^{7}$ & 3.40 & 6.2 & $1800 \pm 800$ \\
6. Fang hu-form vessel, 4039 & $1.09 \times 10^{8}$ & 7.50 & 1.0 & $4100 \pm 2200$ \\
7. Jade censor, 4078 & $1.29 \times 10^{8}$ & 6.45 & 0.4 & $5800 \pm 2500$ \\
\hline
\end{tabular}

as the fire dragons, are worshiped as deities, the water dragons, for example, to ask for rain. The dragon was the symbol of the emperor, as it represents power and strength. The vessels probably originate from a grave of an emperor of the late Eastern Han dynasty, maybe of the Emperor Guangwu (reign 25-57 A.D.). The reign of the early and the late Han dynasty is considered to be the golden era of Chinese history, when, e.g., paper was invented and the silk road was opened.

Table 2 shows the results obtained for the vessels to be tested for their authenticity. The table also gives the results for the Greek laurel wreath and the golden chalice described above.

We obtained specimens of eight Chinese vessels for authenticity tests. The U/Th-He datings of objects 1-6 shown in Fig. 4 yielded ages in the range of 1800-4100 years. Within experimental uncertainties, the obtained "ages" are consistent with a manufacturing time about 2000 years ago. For object 7 , we obtained a too high age, because the gold contained inclusions rich in helium. Object 8 is not shown as it proved to be modern; the analyses of three samples from different places on the object yielded no helium. The owners do not want to have it described, because they want to make further test, as they suspect repair work with modern gold.

\section{Conclusions}

The work presented here is significant for the dating of geologic gold occurrences and for detecting forgeries of antique gold objects. Geologic gold deposits can be dated using the U/ Th-He dating method directly for the gold itself without analyzing associated minerals. We have shown that the results obtained using our dating method are consistent with the geologic period of the investigated gold occurrences. For antique gold objects manufactured by melting the gold, the U/Th-He dating method is a powerful tool to distinguish between authentic and modern gold objects. However, we have to emphasize that precise dating of such objects that are only a few thousand years old is not possible. The quantities of helium present in the small samples available from valuable antiquities is often at the limit of detection for the mass spectrometer used in the analysis. Therefore, the experimental error limits are large. The method represents a test for the authenticity of a gold antiquity. In about one out of four cases, dating is not possible because of impurities containing excess helium. Silicate grains that did not melt when the object was manufactured contain radiogenic helium produced since the gold formed. These grains were included in the gold that formed millions of years ago. We also investigated the possibility of dating ancient silver and bronze objects, but we were not successful, as both modern and ancient objects contain an excess of helium due to impurities.

Acknowledgments The author thanks his colleagues Armin Schaller and Markus Zuber for their help at various stages of the experimental work presented in this publication. The support of the Physics Institute of the University of Bern by allowing us to rent a laboratory and to use its infrastructure is greatly acknowledged.

Open Access This article is distributed under the terms of the Creative Commons Attribution 4.0 International License (http:// creativecommons.org/licenses/by/4.0/), which permits unrestricted use, distribution, and reproduction in any medium, provided you give appropriate credit to the original author(s) and the source, provide a link to the Creative Commons license, and indicate if changes were made.

Publisher's Note Springer Nature remains neutral with regard to jurisdictional claims in published maps and institutional affiliations.

\section{References}

1. Eugster O, Hofmann B, Krähenbühl U, Neuenschwander J (1992) Noble gases in alpine gold: U/Th-He dating and excesses of radiogenic He and Ar. Meteoritics 27:219-220

2. Niedermann S, Eugster O, Hofmann B, Thalmann C, Reimold WU (1993) Dating native gold by noble gas analyses. Lun Planet Sci Conf XXIV:1073-1074

3. Ogden J (2007) The age of gold. Gems and Jewellery 17:12-13 
4. Eugster O, Niedermann S, Thalmann C, Frei R, Kramers J, Krähenbühl U, Liu YZ, Hofmann B, Boer RH, Reimold WU, Bruno L (1995) Noble gases, K, U, Th, and $\mathrm{Pb}$ in native gold. J Geophys Res 100 B12:24,677-24,689

5. Cabral AR, Eugster O, Brauns M, Lehmann B, Rösel D, Zack T, de Abreu FR, Pernicka E, Barth M (2012) Direct dating of gold by radiogenic helium: testing the method on gold from Diamantina, Minas Gerais, Brazil. Geology 41:163-166. https://doi.org/10. 1130/G33751.1

6. Eugster O (1996) Applications for noble gas analyses of gold. Gold Bull 29:101-104
7. Kossolapov AJ, Ivanov AP, Kuznetsov PB (1999) Helium radiogenic clock for dating of archaeological gold. Proc SPIE, 3315, Scientific Detection of Fakery in Art San Jose, CA, SPIE:16-20

8. Eugster O, Kramers J, Krähenbühl U (2009) Detecting forgeries among ancient gold objects using the $\mathrm{U}$, Th-He dating method. Archaeometry 51:672-681

9. Eugster O, Pernicka E, Brauns M, Shukolyukov A, Olive V, Roellin S (2009) Helium, uranium, and thorium analyses of ancient and modern gold objects: estimates of their time of manufacturing. ArcheoSciences, revue d' archéométrie 33:59-65

10. Ball P (2008) Material witness: old gold. Nat Mater 7:694 